\title{
The Soft Skills Hidden in Educational Escape Experiences for Middle School Students: A Case Study in South Texas, USA
}

\author{
Marsha D. Sowell \\ Department of Teacher and Bilingual Education, Texas A\&M University-Kingsville \\ 700 University Blvd., MSC 196, Kingsville, Texas, 78363, United States \\ E-mail: marsha.sowell@tamuk.edu
}

\begin{abstract}
Gamification of the classroom motivates students and improves both academic and soft skills. The use of educational escape games as a form of gamification shows potential in developing students' soft skills such as teamwork, problem solving, and communication skills. This study sought to determine if middle school students engage in similar soft skills experiences while participating in educational escape rooms. An eighth grade English Language Arts teacher and the primary investigator participated in an action research project to design educational escape experiences over the course of eight months for a middle school in South Texas. The goal of the project was to design classroom experiences to engage students in the content curriculum while also encouraging the growth of soft skills (skills such as teamwork and leadership that are desirable and apply across a variety of situations). The research questions guiding this project were: 1) What soft skills do middle school students engage in while participating in an educational escape experience?, 2) How do students engage in the use of these soft skills?, and 3) How can teachers manipulate the escape experience design to include soft skills? Results of the study showed that during educational escape experiences students demonstrated a growth mindset through their motivation to engage in the problem, use of problem-solving skills involving using background knowledge and looking for patterns, and resiliency in completing the challenges. Students believed they could complete the challenges and persisted until the challenge was completed, regardless of beating opponents or winning prizes.
\end{abstract}

Keywords: escape experiences, soft skills, hidden curriculum, innovative teaching, middle school

DOI: $10.7176 / \mathrm{JEP} / 11-14-04$

Publication date:May $31^{\text {st }} 2020$

\section{Introduction}

The term "gamification" became popular in 2010 and the process of gamifying classrooms has grown in popularity since that time (Dichev \& Dicheva, 2017). Simply stated, this means that teachers add elements of game design to classroom experiences in an effort to increase student engagement in the curriculum through an immersive experience (Marti-Perreño et al., 2016; Dichev \& Dicheva, 2017). In theory, gamification motivates students to engage in the learning process, leading to increased student effort and time on task, thus improving academic outcomes. (Dichev \& Dicheva, 2017). Although limited, research supports this claim, indicating that gamification in education increases student academic performance and retention of material when compared to traditional teaching models (Chen et al., 2018; Khan et al., 2017; Piu et al., 2016). One contemporary style of game that teachers are exploring incorporating in the classroom is the escape room. Escape rooms are games full of puzzles that must be solved in a given time limit to 'escape,' or win. For undergraduates, educational escape rooms display unexpected learning results. Educators report that while engaging in the game format, students developed soft skills including teamwork, problem solving, and communication skills (Humphrey, 2017). This study sought to determine if middle school students engage in similar soft skills experiences while participating in educational escape rooms.

\section{Review of Literature}

Gamification, and specifically the escape room format, seems to have the potential to teach a hidden curriculum of soft skills within the middle school. As teachers explore new and relevant methods to teach students, gamification is gaining in popularity. To better understand the value of using gamification, and specifically escape experiences, this review of literature will focus on providing a contextual framework for understanding the hidden curriculum, soft skills, and gamification including educational escape experiences.

\subsection{Hidden Curriculum}

The hidden curriculum of schools can be defined as "the diverse messages received and lessons learned through students' actual engagement with the process of schooling" (McLean \& Dixit, 2018, p. 282). The messages and lessons are learned through social relationships and experiences in the school setting (Arslan \& Akbulut, 2018) and include "aspects of social behavior vital to their [students'] future success in society" (Sulaimani \& Gut, 2019, p. 32). These hidden lessons often have greater influence on students than the formal academic curriculum (Arslan and Akbulut, 2018). 
At one time only the negative hidden curriculum was acknowledged, one in which the lessons taught perpetuated social, racial, and gender inequality. However, researchers now recognize that the hidden curriculum can also teach positive lessons (Alsubaie, 2015; Arslan \& Akbulut, 2018; McLean \& Dixit, 2018; Sulaimani \& Gut, 2019). For example, McLean and Dixit (2018) report that the hidden curriculum in self-help books influenced readers to adopt a more positive and grateful attitude in their lives. Sulaimani and Gut (2019) assert that purposefully integrating the hidden curriculum of societal rules and general community standards into the formal curriculum results in better academic performance for students with autism spectrum disorder. Likewise, Alsubaie (2015) claims when teachers understand the hidden curriculum and how it is enacted in schools, they have the power to use it to embed positive messages, such as the skills needed to succeed in life, into their curriculum.

\subsection{Soft Skills}

Skills that are needed to succeed in life, but are not easily quantifiable are known as 'soft skills' (Beheshti, 2018; Fernandez \& Liu, 2019; Majid et al., 2019; O’Brien \& Pitera, 2019). Sometimes called noncognitive skills, personality traits, social-emotional skills, or applied skills, soft skills are defined by lists of abilities that are desirable and transferable across tasks (Fernandez \& Liu, 2019). Examples of soft skills include collaboration, teamwork, communication, adaptability, leadership, problem solving, resilience, and time management (Beheshti, 2018; Fernandez \& Liu, 2019; Greene, 2016; Majid et al., 2019). Soft skills must be cultivated rather than taught and are not easily measured (Beheshti, 2018), so they are often found in the hidden curriculum rather than the traditional curriculum of schools.

The traditional curriculum in schools focuses on teaching technical, or 'hard' skills. These skills are able to be measured and mastered. Despite school's focus on teaching hard skills, soft skills are increasingly seen as equal to or more important than hard skills (Beheshti, 2018). Majid et al. (2019) conclude that employers believe soft skills are an important factor in hiring decisions. They say that the majority of employers would hire an employee "who has limited technical skills but strong soft skills" (p. 25). Fernandez and Liu (2019) add that there is a positive correlational relationship between the development of soft skills and occupational wages such as promotion and increased wages. In order to provide an effective education, schools must address the teaching of soft skills.

Due to the growing recognition of the importance of teaching soft skills, social-emotional learning (SEL) programs are now being implemented in K-12 schools. These programs serve as a way to implicitly develop social and emotional competencies and prosocial behaviors and attitudes. The purposeful teaching of soft skills through SEL programs yield significant results in developing the social and emotional skills (Boncu et al., 2017). Development of soft skills also shows promise in increasing academic, or cognitive skills. In a study utilizing preand post-tests, Lemberger et al. (2018) report seventh grade students participating in an SEL intervention program demonstrated greater gains in mathematics and reading than students who did not participate in the program.

Programs to develop soft skill must be purposefully developed. Effective middle school SEL programs develop soft skills by connecting students with peers and the school through socialization (Greene, 2016; Lemberger et al., 2018) and integrating the teaching of soft skills with technical (hard) skills (Fernandez \& Liu, 2019). Furthermore, to be effective, lessons must include elements students perceive to be fun and valuable (Lemberger et al., 2018).

\subsection{Gamification and Educational Escape Experiences}

Gamification of the classroom is one method that offers a combined approach to teaching hard and soft skills in a fun and meaningful way. O'Brien and Pitera (2019) explain that gamification offers a shift from lecture-based content learning to "more active, learner-centered models that provide students with transferable attitudes and mindsets, including resilience, persistence, adaptability, problem solving, and teamwork" (p. 193). Turning lessons into games creates a low-risk environment with a culture designed to encourage success, problem solving, and ownership (Clarke et al., 2017; O’Brien \& Pitera, 2019).

Within the realm of gamification in the classroom, educational escape experiences are growing in popularity (Humphrey, 2017; O'Brien \& Pitera, 2019). Escape experiences are hands-on, live-action games that challenge players to complete puzzles and tasks within a given time limit (Nicholson, 2018; Rouse, 2017). A narrative is given for the puzzles and tasks, and once completed, students are able to 'escape' from the situation (Nicholson, 2018). When applied to education, the puzzles and tasks are focused on specific learning objectives (Nicholson, 2018; Stone, 2015). Clarke et al. (2017) explain the purpose of the educational escape experiences is to create "live-action games for the purposes of education and positive behavior change" (p. 75). The inherent design of educational escape experiences combines the teaching of both hard and soft skills.

The puzzles and tasks within educational escape experiences require students to use soft skills by applying critical thinking and problem-solving skills to resolve complex, content related problems. Due to the time restraints of the experience, students are encouraged to work cooperatively with diverse people, recognizing and using other's strengths to win (or lose) as a team. Because they are immersive, action-based experiences, they also prove to be interesting and motivating for students, leading to higher levels of task engagement (Chen et al., 2018; 
Nicholson, 2018; O’Brien \& Pitera, 2019; Rouse, 2017). Time limits for success add urgency to the game and encourage students to participate in tasks and procedures they might find unnecessary in a traditional classroom (Nicholson, 2018; O’Brien \& Pitera, 2019).

Nicholson (2018) reminds us that "educators have already taken advantage of escape games for classroom use. However, as this is a relatively new phenomenon, we are in the early days of exploring how escape games fit into the classroom" (p. 46). Although scarce, research regarding escape experiences in the classroom seems positive (Dichev \& Dicheva, 2017; Humphrey, 2017; Marti-Perreño et al., 2016; O’Brien \& Pitera, 2019; Stone, 2015). Undergraduates participating in an educational escape experience reported development in critical thinking skills, dependency on collaboration with others, communication skills, and resilience (Rouse, 2017). Participants of an educational escape game for computer science engineering students in Spain call the experience challenging, demanding, interesting, and amusing (Borrego et al., 2017). Humphrey (2017) also says feedback from students in higher education "enabled them to develop real-world skills such as teamwork, problem solving, communication, leadership, observational and mathematical skills" (p. 53).

Most literature on gamification and escape experiences in education focus on students of higher education (Dichev \& Dicheva, 2017). This research project will add to the literature on gamification and educational escape experiences in the middle school setting.

\section{Methods}

An eighth grade English Language Arts (ELA) teacher and the primary investigator participated in an action research model to design educational escape experiences for a middle school in South Texas. The goal of the project was to design classroom experiences to engage students in the content curriculum while also encouraging the growth of soft skills. The research questions guiding this project were: 1) What soft skills do middle school students engage in while participating in an educational escape experience?, 2) How do students engage in the use of these soft skills?, and 3) How can teachers manipulate the escape experience design to include soft skills? Answering these questions will add to the body of literature exploring the use of educational escape experiences in the middle school setting.

For the purposes of this study, puzzles refer to clues and codes used to open a single lock. The combined puzzles needed to be solved to open multiple locks and win are referred to as challenges. All the challenges offered in a single class or setting are referred to as experiences. This action research resulted in three experiences with 15 challenges and 40 puzzles. The first experience was created as a cross-curricular experience for a seventh-grade leadership class. The second experience was created with English Language Arts (ELA) curriculum for multiple eighth-grade classes. The final experience was created as a cross-curricular experience for sixth, seventh, and eighth grade gifted and talented students on a field trip.

\subsection{Data Collection}

Within action research, practitioners use practices of traditional research to systemically investigate and solve problems in the real world. Action research is enacted in a cycle: collect data, analyze and interpret data, act on the results, and repeat the process (Glanz, 2014; Stringer, 2014). Throughout an eight-month process, the primary investigator and an ELA teacher worked as a design team to develop educational escape experiences for middle school students. Both members of the design team observed and took field notes as students participated in each experience. Observations allowed the design team to collect a firsthand account of the experience provided to middle school students through the designed games (Merriam, 2009). Documents including puzzles, student work, and planning documents were collected to provide a stable context for the data collected (Erlandson et al., 1993). Finally, interviews in the form of verbal reflections after each planning session and student experience were recorded and transcribed to help bring meaning to the experiences the design team brought to the process (Seidman, 1998). These observational notes, documents, and verbal debriefings served as data to analyze and interpret and then guide future escape experiences. This cycle continued throughout eight months and resulted in 40 puzzles created for 13 escape experiences.

\subsection{Data Analysis}

Data analysis for this project followed a grounded theory approach in which codes and themes were gleaned from the data rather than from preexisting ideas (Glaser \& Strauss, 1967). Utilizing the action research cycle, the design team would continually collect data from experiences, analyze and interpret the data, and then act on the results (Glanz, 2014; Stringer, 2014). After each experience, the game designers would use coding to create shorthand notes of the soft skills students displayed while participating. They then identified features of the experiences that helped encourage these skills and created new experiences to replicate, change, or increase these skills. This method of simultaneous data collection and analysis provided more focused, purposeful data for final analysis (Merriam, 2009).

Upon completion of the eight-month action research cycle, the primary investigator began more formal 
analysis by reviewing each piece of data with its original coding. For each soft skill that was identified, codes were added to the data identifying the method in which students engaged in the skill and the influencing factors for engaging in the skill. This coding was then used to begin reducing the data into similar themes to answer each research questions (Merriam, 2009). This process was repeated multiple times until clear themes emerged in the data as answers to each research question.

\section{Results}

Within educational escape experiences, students have the opportunity to use and refine their soft skills (Clarke et al., 2017; O'Brien \& Pitera, 2019). The way students use soft skills and the way teachers manipulate experiences to include soft skills are both tied directly to the soft skills students use in educational escape experiences. For this reason, the findings of this research are presented according to the skills students displayed within the games. Four overarching themes emerged as soft skills students utilized in educational escape experiences: engaging in the task, working together, applying problem solving skills, and displaying resiliency.

\subsection{Engaging in the Task}

At the beginning of the educational escape experience project, the design team was asked what qualities they believed would make this project a valuable educational tool. The ELA teacher immediately answered, "gamification - students love the challenge in a game. This simply adds to the engagement and 'purpose' of learning. Trick them into engaging in the content!" Game elements are recognized as motivators for engagement in tasks (see Chen et al., 2018; Nicholson, 2018; O'Brien \& Pitera, 2019; Rouse, 2017). Both the possibility of winning and the entertainment of playing the game proved to be valuable game elements in engaging students in educational escape experiences.

Within any game, there is the possibility of winning and losing. In many games, there is also the opportunity to win a prize. Students participating in the educational escape experiences in this middle school seemed to be motivated by the possibility of winning, but not winning a prize. In the first experience, seventh grade leadership students were given three challenges for three similar locked boxes. In the first challenge, the students did not even open the box for the final challenge. Once the final lock was released, the students moved on to the second set of challenges. Thinking the students did not realize there was a prize, one of the game designers showed the students the candy prize inside the final box. While a few students took some candy, most ignored it and moved on to the second box. When the second set of challenges was complete, the students opened the box, said, "more candy" and moved to the third box without even taking a piece. When the final lock was opened on the final box, they did not even open the box to see the prize. They were simply excited that they had "won".

In the final experience for gifted and talented students, however, students were told they had to collect the stickers locked in the last box for nine separate challenges. The object of the experience was to collect all the stickers. In these challenges, students always checked for the prize sticker and sometimes pleaded with the challenge moderator to give them the stickers even if they did not succeed in unlocking the box. These stickers, however, represented yet another challenge rather than a prize. No prizes were given for the teams who collected all the stickers, yet students were not upset. Bragging rights at earning all the stickers seemed to be enough of a prize.

In other instances, it was noted that students did not even ask for prizes, nor did they acknowledge there was no prize for winning. Excitement at the completion of individual puzzles and complete challenges was observed in the form of exclamations such as "Heck, yeah!" accompanied by a fist bump with a teammate. When classes rotated through challenges, students would end the experience by boasting to one another about the time they took to 'escape'. The lower the time, the louder the students would announce it.

Although prizes were offered in the first two experiences, it was quickly recognized that the motivation for engaging in the game was not to earn a prize. Winning, and the associated bragging rights for winning, were motivation enough to play the game and engage in the curriculum necessary to win.

In addition to winning, students' desire to play the game seemed to be a motivator for engaging in the task. In a Halloween-inspired experience for eighth grade ELA classes, students had to be told to wait to start the challenge. As a timed game, they could not start until told to do so, but some were anxiously picking up items and looking for clues as soon as they were within reach of the items. When told they could start, most of the students immediately began the process of looking for clues. In one of these challenges, two students were observed not participating immediately. One boy simply leaned against a wall and watched his classmates play the game. A girl opened a book and started reading.

As his teammates read a pumpkin poem a third time, the boy leaning against the wall pushed off the wall, simply saying, "The pumpkins" as he walked over to join his group. The group noticed that, indeed, the pumpkins looked like they were rolling across the paper and the direction of their stems was the clue to open the directional lock. The boy joined his team for the rest of the challenges in class.

With two girls reading paragraph-long clues aloud, the girl reading a book became distracted. As her 
teammates read, she kept looking over at them until she finally sighed, closed her book and joined them. With a new viewpoint, this student immediately recognized that the clues needed to be alphabetized by author's last name. Directing her teammates, the three girls ordered the clues, and opened the associated lock. The book was not touched again as all three girls continued working on their escape challenges for the rest of class.

While most students were immediately interested in beginning the game, reluctant students were drawn into the game. Whether interested in the novelty of an educational escape experience or the challenge of winning a game, no student refused to participate in the challenges throughout the eight-month process. When given the opportunity, reluctant or not, every student chose to participate in playing the games.

\subsection{Working Together}

One of the reasons the primary investigator decided to proceed in this project was the dependency on teamwork required for success in commercial escape rooms. One game designer explained that it was the teamwork element that sparked her interest in escape experiences as educational tools. She explained:

An ex-superintendent told me that he noticed people who were not friends did better [succeeding in commercial escape rooms] because they had different thinking patterns and were able to work collaboratively. When people didn't know each other, everyone works towards the same goal, but kind of do their own thing and ask for help as needed. When people try to do escape rooms with their friends, they work cooperatively. The whole group works on one thing together. This interests me because there is a balance between the two - a splitting of responsibilities mixed with the need to use everyone's brains!

The element of collaboration and teamwork celebrated in gamification research (Beheshti, 2018; Fernandez \& Liu, 2019; Greene, 2016; Majid et al., 2019, Rouse, 2017) was also recognized in this project through the division of responsibilities and recognition of value in classmates' strengths.

One of the key aspects the game designers noticed early on was that the game design needed to create several opportunities for students to work on different things at the same time. The ELA teacher acting as a game designer explained games needed to offer multiple paths, "not just linear where you have to do ' $A$ ' and then ' $B$ ' and then ' $\mathrm{C}$ ' because that keeps it from being accessible to a lot of students. If you have ten students on a team, you want ten people working. You want everyone working on pieces so that you can solve these things in order or out of order.” Nicholson (2015) refers to this as an 'open' style game.

This teacher's insight proved to be beneficial as students divided responsibilities within their groups. When first getting a challenge with three locks, a group of six students immediately separated into three groups of two students each. When they could not solve the puzzles in their small groups, they started exchanging papers and then looking at multiple clues to see if they went together. As a small group solved one puzzle, they joined another group to make a group of four. As a second lock was opened, all of the students moved to put their minds together in solving the final puzzle. Throughout the challenges all six students were engaged in the process of solving the puzzles.

In addition to dividing the thinking elements of the game, students also divided responsibilities in the manipulation of the game pieces. In one particular challenge, the group realized that the information they needed was written on film in a canister, but the film kept rolling up and could not be read. One student took the lead and told her teammate to hold the film canister and the end of the film to keep it from rolling up. Another student immediately began reading the information off the film. A third student, consulting the coordinating clue on a math table, identified and called out the relationship. Two other students used their fingers to follow the clues on the graph and called out the agreed upon code. The 'leader', entered the code into the lock. Together this team was able to open the lock.

In both separating the puzzles to solve them more efficiently and in working together to manipulate puzzle pieces, the students demonstrated the ability to divide responsibilities among teammates in educational escape experiences.

When dividing responsibilities, students often utilized one another's strengths as a resource. When two eighth-grade girls could not figure out the solution to a spider web clue, they handed the clue off to another teammate and said, "Here, you're good at puzzles. You try it." This teammate quickly figured out the code and showed her teammates how it was solved. Together, the three opened the lock and moved to the next puzzle.

Student comments such as, "You do that one, you're good at math" and "I'll read this. I like reading" demonstrated students' recognition of each other's strengths throughout the project. New strengths were also realized through winning challenges. When the boy who was leaning against the wall originally spoke up to help, his teammates looked astonished at his participation and knowledge. In other instances, teammates made comments such as, "Wow! Y'all are so smart! How did you do that?" when locks were opened quickly.

The value of others was one of the elements teachers sought to embed in the escape experiences. One designer commented:

Due to the nature of the game, it is difficult for one person to be able to change and think in different ways. With multiple minds and multiple puzzles, different people's strengths will be needed. Thus, the usually poor 
student may have the opportunity to shine whereas the usual 'brain' may be able to give content knowledge but struggle with the creative elements. This will encourage everyone in recognizing the strengths of others. Strengths that are not always apparent in a traditional classroom setting.

Students demonstrated teamwork and the ability to work collaboratively with others by dividing responsibilities and utilizing one another's strengths to efficiently solve puzzles and complete challenges. Although this was one element purposefully built into the experiences, student's comments demonstrated their awareness of the importance of working together as well.

\subsection{Applying Problem Solving Skills}

The purpose of any escape experience is to solve puzzles in a set time period to escape (Nicholson, 2018). To solve the puzzles, game participants must use critical thinking and problem-solving skills (Humphrey, 2017; Rouse, 2017). For one game designer, this use of critical thinking skills was the driving force in implementing escape rooms as an educational tool. She said:

The puzzles require knowledge, but also logic. Putting these two items together is imperative in real-life, so it can give students experience in looking at something from different viewpoints or for different uses. While there is a specific answer, it is not as clearly defined as a worksheet makes it out to be. The students have to think critically to make it out.

In this study, students were able to put together their knowledge and logic to complete the puzzles and the challenges. Students used their background knowledge as well as patterns within the puzzles to successfully escape.

Students come to school with knowledge from the outside world. In one challenge, a student used this knowledge to decide how to read and solve a clue. The clue said, "\#bats, \#owls, \#ghosts". Upon seeing this, students immediately cried out, "Hashtag is a hint!" When this did not prove to be beneficial to figuring out the challenge, one student exclaimed, "Oh! My mom says that's a number sign!" The group immediately started counting the number of bats, owls, and ghosts in the decorated room and solved the challenge.

In addition to personal background knowledge, the educational escape experiences required students to combine their content knowledge with logic. One puzzle required students to order historical events, but the students were unsure of the actual order of events. In this challenge, the seventh-grade students verbalized their thinking with comments such as "I know this is last because it is Obama", "This one has technology so it has to be later," and "World War I is obviously before World War II." Through this type of thinking, students were able to correctly figure out the order of the events without remembering the specific event dates.

Through both personal background knowledge and content prior learning, combined with logic, students were able to successfully complete challenges. This is the type of critical thinking and application of knowledge teachers want students to develop.

When background knowledge did not prove to provide answers, students often looked for patterns in the puzzles. In one experience, students were given three locked box challenges with three puzzles for each box. The puzzles were identical in their content and presentations, but not in their theme. When the student group found the first map, they looked all over the paper, searching for hidden messages, following the directions to the "treasure", and using the black light to uncover secrets. When none of this worked, they carefully read the text and noticed several numbers were substituted for letters - these numbers were the code. Upon finding a similar map in the next locked box, the students recognized the challenge and solution. They did not even read the text, but simply searched for hidden numbers.

Students also looked at the locks as a pattern clue for solving puzzles. One group of students was having a difficult time solving the skeleton poem puzzle. A student noticed that the remaining lock had both numbers and letters, so she suggested her group searched for hidden numbers and letters. They found these hidden clues almost immediately upon her suggestion and opened the lock. In another puzzle, students saw dates on a block of text. A previous puzzle had the students put the pieces together and use the years as the code for opening the lock. This group started to repeat the action, but recognized that there were too many digits for the lock this way. Although looking for the pattern in the puzzles had worked in previous challenges, it did not help them this time!

In engaging with the educational escape experiences, students engaged in critical thinking in many ways. They used their background knowledge and prior learning, combined with logic and following patterns, to solve puzzles. When one way failed to be successful, students did not give up but would try another way.

\subsection{Displaying Resiliency}

O'Brien and Pitera (2019) note that one of the benefits of using gamification in education is that students develop resiliency. This was demonstrated in this study as well. Although neither game designer acknowledged this benefit when beginning the project, they recognized it in the end.

In one challenge, the students revisited a puzzle three times before successfully opening the lock. At first students quickly scanned the clues, and finding no easy answer, they put the clue cards down and moved to another puzzle. One of the teammates came back to the cards a few minutes later and suggested they use the dates to order 
the cards. The group completed this task and used the order of the background colors of the cards to open the lock. It did not work. The whole group moved to another puzzle. A few minutes passed and a different teammate moved to the difficult puzzle again. She looked back and forth from the puzzle, still in order by date, to the lock. Turning the lock over, she recognized the team had put the code in backwards. She put the code in correctly and opened the lock. Although the group moved away from the puzzle twice, it was apparent students were still thinking about it and considering solutions. They did not give up. This pattern of putting clues to the side and trying different puzzles, but then coming back, was repeated in every challenge. Nicholson (2018) points out that this is one of the benefits of open designed educational escape experiences. Students do not feel they have to follow exact steps to solve the problems, but can freely move between puzzles and have time to think and process while still moving ahead.

Through participation in educational escape experiences, students displayed engagement in academic tasks, worked together, applied problem solving skills to difficult situations, and demonstrated resiliency in task completion.

\section{Discussion}

Soft skills such as collaboration, teamwork, communication, adaptability, leadership, problem solving, resilience, and time management (Beheshti, 2018; Fernandez \& Liu, 2019; Greene, 2016; Majid et al., 2019) are not considered a part of the traditional academic curriculum. They are, however, taught as part of the hidden curriculum through students' engagement in the processes of education (Arslan \& Akbulut, 2018; McLean \& Dixit, 2018; Sulaimani \& Gut, 2019). As soft skills become increasingly important to students' futures (Beheshti, 2018; Majid et al., 2019), teachers must find ways to bring these lessons out of hiding by purposefully integrating the teaching of soft skills with the teaching of content in fun and valuable ways (Fernandez \& Liu, 2019; Greene, 2016: Lemberger et al., 2018).

Teachers are exploring educational escape experiences as a fun way to teach content while providing students the opportunity to purposefully develop soft skills (Humphrey, 2017; O'Brien \& Pitera, 2019). Although limited, research demonstrates growing popularity and positive outcomes from the use of educational escape experiences in K-12 classrooms (Dichev \& Dicheva, 2017; Nicholson, 2018). This study adds to the literature supporting the use of educational escape experiences as a classroom practice for engaging middle school students in the use and development of soft skills.

\subsection{Soft Skills Recognized in Educational Escape Experiences}

Through the use of educational escape experiences students displayed multiple soft skills including a growth mindset, problem-solving skills, teamwork, and leadership.

As students participated in educational escape experiences, they demonstrated a growth mindset. Dweck (2019) explains that the growth mindset refers to individual's belief that they can develop their skills and talents to achieve more. Because they believe they can grow, individuals with a growth mindset find the process of learning valuable. Even students who initially did not want to participate in the educational escape experience were drawn into the challenge of the game, willingly engaging in the process of learning. Students continued to engage until the end of the game, regardless of whether a prize was offered or not. They valued the learning experience for the experience itself, not for what it offered them. Further demonstrating a growth mindset, students continually returned to puzzles they could not solve on their first attempt. Combining problem-solving skills and teamwork with background knowledge, prior learning, and the patterns found in the game, students believed they could solve the challenge and escape within all the given time limits. Students' willingness to engage in the learning process, resiliency to complete the task, and application of critical thinking skills to solve challenges all demonstrate the growth mindset apparent in educational escape experiences.

In addition to the growth mindset, students demonstrated an internal motivation to succeed when participating in educational escape experience. This internal motivation is seen as students have to be told to wait to begin the challenge and again as they choose to engage rather than remain separate from the group. Their apparent lack of interest in a prize for their success further shows the internal satisfaction at completing a challenge. Even the process of completing puzzles that were similar rather than stopping the game demonstrates an internal drive to engage with the content of the game.

Although an expected outcome, students recognized the value of teamwork within the educational escape experiences. As students' desire to succeed within the time limit became apparent, so did their need to rely on one another for that success. As Nicholson (2018) claims, in educational escape experiences students win or lose as a team. To complete the challenge and win, participants moved between the collaborative and cooperative models of engagement. At first, students would divide tasks for better time management. For example, five different team members read clue cards, but when someone mentioned putting them in order by year, they all came together to complete this task. This divide and conquer strategy demonstrated their collaborative attitude. However, as students worked through problems as a team, such as the film canister puzzle requiring the entire team for one 
puzzle, they also demonstrated a cooperative attitude. Moving between collaboration and cooperation, students traded clues, discussed ideas for solving puzzles, and asked for help when individuals were not able to solve puzzles alone. When a particular skill-set was needed to solve a puzzle, students asked teammates with those skills to step in and take the lead on that puzzle. Working in an educational escape experience as a group challenge, students were able to combine collaborative and cooperative attitudes to recognize value each other's strengths and ideas rather than working alone or in competition with one another.

The value of teamwork highlighted another soft skill students encountered in the educational escape experiences: leadership. As previously mentioned, through teamwork students depended on one another's skills and asked their teammates to take the lead on individual puzzles. This behavior encouraged students who do not generally take leadership roles to step into that role, if only for a few minutes. In most puzzles, the individual who first understood how to get to an answer would step into the leadership role. This was demonstrated as the girl reading a book on the side joined her team and led them in alphabetizing the author's biographies. In other instances, such as the film canister puzzle, natural leaders emerged to move the process forward. Educational escape experiences gave students opportunities to recognize and develop their leadership skills.

Results of this study indicate that during educational escape experiences students demonstrate a growth mindset, increase internal motivation to complete tasks, value teamwork, and take on leadership roles.

\subsection{Methods of Engaging in Soft Skill Use}

Gamification of the classroom encourages students to engage with curriculum (Dichev \& Dicheva, 2017). The results of this study indicate the game elements of educational escape experiences also lead students to engage with soft skills. The design of the challenges, feedback from locks, and the frustration of the challenge lead students to apply their soft skills.

The design of challenges led students to display the value of teamwork, time management, resiliency, and problem-solving skills. Unlike traditional assignments where problems can be skipped and minimum performance standards met, in an escape challenge students must use all of the clues and solve every puzzle to succeed. When challenges are created in an open concept, students are able to work on multiple elements at one time (Nicholson, 2018). The addition of a time limit creates urgency in the game and further encourages students work together to be successful (Nicholson, 2018; O’Brien \& Pitera, 2019). These middle school students employed teamwork and time management skills by dividing clues immediately in each challenge. Furthermore, the open concept allows students to move between tasks, increasing both processing and thinking time without sacrificing actual time. By the nature of escape games, students engage in problem solving by taking clues, putting them together, and completing the challenge to escape. For example, students realized they could not solve a puzzle regarding historical events alone or even with the direct knowledge they possessed. However, with the pieces of prior learning and logic from the group, they were able to determine the order of events and solve the puzzle. Like others report ((Chen et al., 2018; Nicholson, 2018; O’Brien \& Pitera, 2019; Rouse, 2017), the fun and challenge presented by the opportunity to win, combined with a specific time limit in an action-based, immersive experience encouraged students to remain resilient and complete the tasks. The bragging rights, smiles, and conversations regarding their winning strategies attest to the students' internal motivation to continue the tasks to completion.

As puzzles are solved in escape experiences, players enter the answers into locks. To escape, participants must open every lock. This format allows locks to give participants immediate feedback. If the lock opens, they are on the right track and making progress toward the goal. This progress encourages students to continue in their task. If a lock does not open, game players need to rethink the puzzle. In this study, students were able to revisit a lock to find that they had simply put the code in incorrectly rather than having a solution wrong. Students were also able to use the locks as clues, such as when students noticed the lock required both numbers and letters to solve the skeleton puzzle. The locks in educational escape experiences encourage students to look at things in new ways, encouraging reflection, critical thinking and problem solving.

The challenge and frustration of the puzzles within the experiences led students to use others as a resource and to apply critical thinking to solve the problems. Educational escape experiences are not designed to give students all of the information in a straight-forward manner. Clues are hidden or separated and must be discovered. Sometimes clues are simple, such as numbers substituted as letters in the treasure map. After searching the paper, following the directions, and using the black-light to search for hidden messages, two students asked their teammates for help. This new viewpoint quickly led to recognition of the number switch and a solved puzzle. This situation played out throughout the challenges as students would be ready to give up on a puzzle, but not on the challenge. They would move to another puzzle for a moment and call on teammates to help solve the problems. Although the challenge sometimes frustrated the students, they never asked to give up.

The game format, the challenges of the puzzles, and even the locks within educational escape experiences encourage students to use soft skills to complete the challenges presented. 


\subsection{How can teachers manipulate the escape experience design to include soft skills?}

Because the puzzle design encourages students to develop soft skills, teachers can manipulate the puzzles to enhance these lessons. Challenges need to be designed in an open format so multiple puzzles are being worked on at one time (Nicholson, 2015). For this project, this meant that clues for most puzzles were readily available although hidden. When students opened each of the three to four locks available they found a single clue. The clues locked away went together for one culminating lock. This open concept allows multiple students to engage in the process at one time as there are several clues and locks to decode. It also encourages teamwork as every lock has to be opened in order for the team to win as a group.

Puzzles and challenges can be designed to enhance the strengths of students while encouraging teamwork. We recognized this process as students handed over the math puzzles to students who were known for their math skills and readers kept the puzzles requiring reading. Student strengths do not have to be limited to content knowledge. For example, a native Spanish speaker may be needed to decipher a code using Spanish words while a musician would be needed to decipher a code using music notes. These are not skills everyone in the class will possess, but with teamwork students can utilize and encourage each other's strengths to win.

Incorporating multiple types of thinking and different levels of challenge is also important. When the game designers offered three similar challenges, students became less engaged and simply went through the process of opening the locks. Although this demonstrated a transfer of skills from one puzzle to another, it decreased the thinking and teamwork required to be successful. The novelty offered in each experience enhanced the engagement in the task, the critical thinking skills employed, and the teamwork needed. Each challenge in this study offered at least one 'quick-win' puzzle. These puzzles, such as the pumpkin stems rolling, offered students an opportunity to be encouraged in their progress as they quickly opened a lock. Because educational escape experiences should be used as a teaching tool rather than just fun, and because students are motivated by the challenge inherent in games, challenging puzzles with rigorous content need to be offered as well. Puzzles can be created so students use background knowledge, prior content learning, or problem solving skills. Challenging puzzles combine these types of knowledge to provide the greatest amounts of student engagement and teamwork. In the "\#bats, \#owls, \#ghosts" puzzle, the process of counting was simple but the use of background or common knowledge added a bit of challenge to the puzzle as students had to recall that "\#" can be a hashtag or a number sign. The more challenging mathematics graphs puzzle required students to combine prior content learning regarding graphs, tables, and verbal expressions with problem-solving skills to combine the information. Background knowledge allowed the students recognize the need to pull the film from the canister and access the clues.

In this balance of easy and challenging puzzles, teachers need to be aware of appropriate time limits. The challenges in this study were designed to be completed in approximately 20 minutes and included three to four puzzles combined with one culminating puzzle. At least one puzzle in each challenge was simple while at least one offered a rigorous challenge. The first challenges took longer as students navigated the new learning format. With experience, students were able to adjust their thinking faster and puzzles took less time. Familiarity with puzzles and locks also decreased the time needed to complete the challenges. Distractors (information available but not needed to solve puzzles) and hidden clues required more time, but provided more frustration. Given the short time frame, students became frustrated when they could not start solving the puzzles because they could not find the information. As this did not enhance student's time on task engaged in content, the puzzle designers stopped adding in distractors and hiding clues in difficult places.

When creating educational escape experiences, teachers can provide students with more opportunities to use soft skills. Designing challenges in an open concept, utilizing students' strengths, offering a variety of puzzles, and providing appropriate time to challenge students should guide the design process.

\section{Implications}

The use of educational escape experiences in middle schools can be beneficial to the growth of students' social emotional soft skills. Within the context of this study, students displayed engagement in the tasks offered, worked as a team, applied problem-solving skills, and displayed resiliency. As such, teachers and administrators should explore escape experiences as an educational tool.

\subsection{Implications for Teachers}

Educational escape experiences show promise of engaging students in the content while developing their soft skills. Teachers are encouraged to create these experiences for their students. While commercial products are available, the experiences will be more meaningful if they are designed with the specific strengths of the class in mind. Teachers may start with a commercial experience, but adapt it in a manner to suit their own students.

When creating or adapting experiences, teachers need to ensure that multiple students may participate at one time in the game. Open concept games encourage this, as does dividing students into small groups to participate in different challenges at the same time. Games should be designed with students' strengths in mind to encourage teamwork and recognition of classmates strengths. Puzzles need to be created with a focus on diverse thinking 
skills. While some puzzles should be easy for motivation, others should offer students a challenge and opportunity to think critically.

One element of educational escape experiences not utilized in this study, but recommended is the inclusion of a time for reflection for students. A reflection of learning helps students personalize and internalize lessons, this is true not only of content but also of soft skills. When designing educational escape experiences, teachers should incorporate a time for students to reflect on the skills they used to solve problems as well as the value of these skills. This purposeful focus on soft skills will help students take ownership in these skills (Boncu et al., 2017).

\subsection{Implications for Administrators}

Educational escape experiences show promise of developing students' soft skills while advancing the content. Because this is still a relatively new practice (Nicholson, 2018), it is not yet proven. Administrators need to encourage teachers to explore this learning opportunity and to help add to the research regarding the practice.

As teachers design escape experiences, they develop a deeper understanding of the content, focus on student strengths and needs, and take ownership of their classrooms. As students participate in educational escape experiences they engage with content while developing soft skills. Administrators need to promote this type of lesson throughout all of education.

To promote the development of educational escape experiences, administrators should offer funding to buy supplies such as locks, boxes, and supplies for clues. Furthermore, teachers should be encouraged to work together to promote teamwork and create cross-curricular learning opportunities. Like students, teachers also need to be given a specific time to reflect on the successes and failures of the experiences. By allowing teachers to reflect and improve on difficulties, administrators model a growth mindset for both teachers and students.

\section{Recommendations for Future Research}

This project was an exploratory case study that added to the body of literature regarding the use of educational escape rooms. The findings of this study highlight several areas in which to conduct future research.

Future research should include student feedback on the process of participation in educational escape experiences. This feedback should include students' perceptions of the game elements impacting their success and internalization of both knowledge and skills. This might be accomplished through the recommended end reflections in the form of focus groups, individual interviews, or written responses to the experience.

Additionally, pre- and post-assessments can be used to determine the extent of students' understanding of content as well as soft skills. These assessments may also be used to determine students' comfort level with specific, targeted skills.

Learning soft skills is only beneficial when students take these lessons and apply them in a variety of contexts. Further studies could include observing classrooms after experiences to determine if students transfer these skills to the classroom. If a transfer of skills is found, researchers should seek to explain how this transfer manifests in the classroom and how many experiences are needed to see this transfer begin.

As soft skills becoming increasingly important, it is important for schools to identify ways to enhance and develop students' soft skills. A thoughtfully planned, content-based educational escape experience is one tool teachers can use to engage and develop students' soft skills in the classroom. Future research in the form of student feedback, pre- and post-assessments, and observations of skill transfer is needed to determine how to best use this tool to impact students.

\section{References}

Alsubaie, M. A. (2015). Hidden curriculum as one of current issue of curriculum. Journal of Education and Practice, 6(33), 125-128.

Arslan, S., \& Akbulut, N. (2018). Hidden curriculum and educational stress. Kastamonu Education Journal, 26(4), $1111-1119$

Beheshti, N. (2018). Are hard skills or soft skills more important to be an effective leader? Forbes. https://www.forbes.com/sites/nazbeheshti/2018/09/24/are-hard-skills-or-soft-skills-more-important-to-bean-effective-leader/\#1e20003a2eb3

Boncu, A., Costea, I., \& Minulescu, M. (2017). A meta-analytic study investigating the efficiency of socioemotional learning programs on the development of children and adolescents. Romanian Journal of Applied Psychology, 19(2), 35-41.

Borrego, C., Fernandez, C., Blanes, I., \& Robles, S. (2017). Room escape at class: Escape games activities to facilitate the motivation and learning in computer science. Journal of Technology and Science Educaiton, $7(2), 162-171$.

Chen, M., Tseng, W., \& Hsiao, T. (2018). The effectiveness of digital game-based vocabulary learning: A framework-based meta-analysis. British Journal of Educational Technology, 49(1), 69-71.

Clarke, S., Peel, D.J., Arnab, S., Morini, L., Keegan, H., \& Wood, O. (2017). escapED: A framework for creating 
educational escape rooms and interactive games for higher/further education. International Journal of Serious Games, 4(3), 73-85.

Cunningham, W., \& Villasenor, P. (2016). Employer voices, employer demands, and implications for public skills development policy connecting labor and education sectors. World Ban Research Observer, 31(1).

Dichev, C., \& Dicheva, D. (2017). Gamifying education: What is known, what is believed and what remains uncertain: A critical review. Journal of Educational Technology in Higher Education, 14(9), https://doi.org/10.1186/s41239-017-0042-5

Dweck, C. (2019). What having a "growth mindset" actually means. Harvard Business Review, Special Issue, 2627.

Erlandson, D. A., Harris, E. L., Skipper, B. L., \& Allen, S. D. (1993). Doing naturalistic inquiry: A guide to methods. Sage Publications, Inc.

Fernandez, F., \& Liu, H. (2019). Examining relationships between soft skills and occupational outcomes among U.S. adults with - and without - university degrees. Journal of Education and Work, 32(8), 650-664. https://doi.org/10.1080/13639080.2019.1697802

Glanz, J. (2014). Action research: An educational leader's guide to school improvement (3 ${ }^{\text {rd }}$ ed.). Rowman \& Littlefield.

Glaser, B. G., \& Strauss, A. (1967). The discovery of grounded theory: Strategies for qualitative research. Aldine Publishing.

Greene, J. (2016). Soft skills: Preparing kids for life after school. AMLE Magazine, 3(6), 48-54.

Humphrey, K. (2017). The application of a serious, non-digital escape game learning experience in higher education. Sport \& Exercise Psychology Review, 13(2), 48-54.

Khan, A., Ahmad, F. H., Malik, M. M. (2017). Use of digital game based learning and gamification in secondary school science: The effect on student engagement, learning and gender difference. Education and Information Technologies, 22(1), 2767-2804.

Lemberger, M. E., Carbonneau, K. J., Selig, J. P., \& Bowers, H. (2018). The role of social-emotional mediators on middle school students' academic growth as fostered by an evidence-based intervention. Journal of Counseling \& Development, 96(1), 27-40. https://doi.org/10.1002/jcad.12175

Majid, S., Eapen, C. M., Aung, E. M., \& Oo, K. T. (2019). The importance of soft skills for employability and career development: Student and employers' perspectives. IUP Journal of Soft Skills, 13(4), 7-39.

Merriam, S. (2009). Qualitative research: A guide to design and implementation. Jossey-Bass Publishers.

Marti-Perreño, J., Mèndez-Ibàñez, E., \& Alonso-Arroyo, A. (2016). The use of gamification in education: A bibliometric and text mining analysis. Journal of Computer Assisted Learning 32(6). https://doi.org/10.1111/jcal.12161

McLean, S., \& Dixit, J. (2018). The power of positive thinking: A hidden curriculum for precarious times. Adult Education Quarterly, 68(4), 280-296. https://doi.org/10.1177/0741713618777817

Nicholson, S. (2015). Peeking behind the locked door: A survey of escape room facilities. https://scottnicholson.com/pubs/erfacwhite.pdf

Nicholson, S. (2018). Creating engaging escape rooms for the classroom. Childhood Education, 94(1), 44-49. https://doi.org/10.1080/00094056.2018.1420363

O’Brien, K. \& Pitera, J. (2019). Gamifying instruction with engaging students with Breakout EDU. Journal of Educational Technology Systems, 48(2), 192-212. https://doi.org/10.1177/0047239519877165

Piu, A., Fregola, C., \& Barbieri, B. (2016). Geometry classrooms with simulations/games. Research results and future developments. Simulations \& Gaming, 47,(6), 796-817. https://doi.org/10.1177/1046878116665464

Rouse, W. (2017). Lessons learned while escaping from a zombie: Designing a Breakout EDU game. The History Teacher, 50(4), 553-564.

Seidman, I. (1998). Interviewing as qualitative research: A guide for researchers in education and social science $\left(2^{\text {nd }}\right.$ ed.). Teachers College Press.

Stone, Z. (2015, July 28). The rise of educational escape rooms: Why UV lights and padlocks are finding their way into classrooms. The Atlantic. https://www.theatlantic.com/education/archive/2016/07/the-rise-ofeducational-escape-rooms/493316/

Stringer, E. T. (2014). Action Research (4 ${ }^{\text {th }}$ ed.). Sage Publications, Inc.

Sulaimani, M.F., \& Gut, D. M. (2019). Hidden curriculum as a special education context: The case of individuals with autism. Journal of Educational Research and Practice, 9(1), 30-39. 